TITLE:

\title{
Direct observation of fine structure in ion tracks in amorphous Si3N4 by TEM
}

$\operatorname{AUTHOR}(S)$ :

Nakajima, K.; Morita, Y.; Suzuki, M.; Narumi, K.; Saitoh, Y.; Ishikawa, N.; Hojou, K.; Tsujimoto, M.; Isoda, S.; Kimura, K.

\section{CITATION:}

Nakajima, K.... [et al]. Direct observation of fine structure in ion tracks in amorphous Si3N4 by TEM. Nuclear Instruments and Methods in Physics Research Section B: Beam Interactions with Materials and Atoms 2012, 291: 12-16

ISSUE DATE:

2012-11

URL:

http://hdl.handle.net/2433/162897

\section{RIGHT:}

C 2012 Elsevier B.V.; この論文は出版社版でありません。引用の際には 出版社版をご確認ご利用ください。; This is not the published version. Please cite only the published version. 


\section{Direct Observation of Fine Structure in Ion Tracks in Amorphous $\mathrm{Si}_{3} \mathrm{~N}_{4}$ by TEM}

K. Nakajima ${ }^{1}$, Y. Morita ${ }^{1}$, M. Suzuki ${ }^{1}$, K. Narumi ${ }^{2}$, Y. Saitoh ${ }^{2}$, N. Ishikawa ${ }^{3}$, K. Hojou $^{4}$, M. Tsujimoto $^{5}$, S. Isoda ${ }^{5}$ and K. Kimura ${ }^{1, *}$

${ }^{1}$ Department of Micro Engineering, Kyoto University, Kyoto 606-8501, Japan

${ }^{2}$ Takasaki Advanced Radiation Research Institute, Japan Atomic Energy Agency, 1233

Watanuki-machi, Takasaki, Gumma 370-1292, Japan

${ }^{3}$ Nuclear Science and Engineering Directorate, Japan Atomic Energy Agency, Tokai, Naka, Ibaraki 319-1195, Japan

${ }^{4}$ Advanced Science Research Center, Japan Atomic Energy Agency, Tokai, Naka, Ibaraki 319-1195, Japan

${ }^{5}$ Institute for Integrated Cell-Material Sciences, Kyoto University, Kyoto 606-8501, Japan

*e-mail: kimura@kues.kyoto-u.ac.jp

Thin films of amorphous $\mathrm{Si}_{3} \mathrm{~N}_{4}$ (thickness $20 \mathrm{~nm}$ ) were irradiated with $120-720 \mathrm{keV} \mathrm{C}_{60}{ }^{+, 2+}$ ions and observed using transmission electron microscopy (TEM). The ion track produced in an amorphous material was directly observed by TEM. For quantitative analysis, the ion tracks were also observed using high-angle annular dark field scanning transmission electron microscopy (HAADF-STEM). The observed ion track consists of a low density core (radius $\sim 2.5 \mathrm{~nm}$ ) and a high density shell (width $\sim 2.5 \mathrm{~nm}$ ), which is very similar to the ion tracks in amorphous $\mathrm{SiO}_{2}$ irradiated with high energy heavy ions observed by small angle x-ray scattering (SAXS). Although the observed ion tracks may be affected by surface effects, the present result indicates that TEM and HAADF-STEM have potential to observe directly the fine structures of ion tracks in amorphous materials. 


\section{Introduction}

The discovery of ion tracks dates back to 1959 when the tracks produced by single fission fragments from ${ }^{235} \mathrm{U}$ in mica were observed by transmission electron microscopy (TEM) [1]. Since then, ion tracks have been observed in various materials irradiated with swift heavy ions, including insulators $[2,3]$, semiconductors $[4,5]$ and metals $[6,7]$ when the electronic stopping power $S_{\mathrm{e}}$ is larger than a material dependent threshold value $[8,9]$. The radius of the ion track increases with the electronic stopping power, indicating that the inelastic process is responsible for the ion track formation. There are several models proposed to explain the observed results, i.e. inelastic thermal spike model, Coulomb explosion model, bond weakening model and exciton self-trapping model. Among these models, the inelastic thermal spike model seems most promising, which quantitatively explains the evolution of the track radius with the electronic stopping power and the threshold stopping power for the track formation. However, because of the lack of information on non-equilibrium thermodynamical properties the applicability of the thermal spike concept is still under debate $[10,11]$.

In case of crystalline materials, the structure of the ion track can be easily observed by TEM. The track interior is amorphized or comprised of defect clusters depending on the material. In case of amorphous materials, direct TEM observation of ion tracks is difficult due to a lack of sufficient contrast. Indirect methods, such as Fourier transform infrared spectroscopy (FTIR) [12, 13] and etching [13, 14], have been almost exclusively used to study the ion tracks in amorphous materials. In the data analysis of FTIR, a simple cylindrical structure is always assumed. This does not allow to deduce detailed structures of ion tracks unlike TEM observation.

Recently, small angle x-ray scattering (SAXS) is employed to study a fine structure of ion tracks in amorphous $\mathrm{SiO}_{2}\left(\mathrm{a}-\mathrm{SiO}_{2}\right)[15,16]$. A clear peak was observed in the SAXS spectra of a-SiO 2 irradiated with $27-1430 \mathrm{MeV} \mathrm{Au}$ and Xe ions. The observed SAXS spectra were analyzed using a simple model structure of the ion track, i.e. a step-function-like radial density distribution. It was shown that a low density cylindrical core surrounded by a high density shell reproduces the observed SAXS spectra. The core-shell structure is 
qualitatively in agreement with the results of molecular dynamics (MD) simulations [16, 17], although the simulated density distribution is not so simple as was assumed in the SAXS analysis. The origin of the core-shell structure was suggested to be the density anomaly existent in $\mathrm{a}-\mathrm{SiO}_{2}$, i.e. densification of $\mathrm{a}-\mathrm{SiO}_{2}$ above $1800 \mathrm{~K}[16,18]$. It is noteworthy that the opposite density change, i.e. a high density core surrounded by a low density shell, cannot be excluded by the SAXS measurement because such a density distribution gives the same SAXS spectrum. In addition, SAXS as well as FTIR provide only average structural properties of the ion tracks. Thus, direct observation of the track structure by TEM is still highly desired to determine the detailed track structures without ambiguity and to understand the mechanism of the track formation.

The SAXS result showed that the density of the track core is as low as $40 \%$ of the bulk density of $\mathrm{SiO}_{2}$ for $185 \mathrm{MeV} \mathrm{Au}$ ion impact. The MD simulation predicted even larger density reduction at the track center (95\% reduction) when the electronic stopping is 18 $\mathrm{keV} / \mathrm{nm}$. Such large density reduction should be easily observed by TEM. Actually, there were several studies on the ion tracks produced in metallic glasses by high energy ions using TEM [19, 20]. However, as we will discuss below, quantitative estimate of the density change is difficult by TEM. In the present paper, we report on direct observation of the ion tracks in amorphous $\mathrm{Si}_{3} \mathrm{~N}_{4}$ irradiated with $120-720 \mathrm{keV} \mathrm{C}_{60}{ }^{+,}{ }^{2+}$ ions using TEM and high-angle annular dark field scanning transmission electron microscopy (HAADF-STEM). The radial density distribution of the ion track can be easily derived from the observed HAADF-STEM images.

\section{Experimental}

Self-supporting amorphous $\mathrm{Si}_{3} \mathrm{~N}_{4}\left(\mathrm{a}-\mathrm{Si}_{3} \mathrm{~N}_{4}\right)$ films of thickness $20 \mathrm{~nm}$ were purchased from Silson Ltd, which were prepared by chemical vapor deposition on Si wafers. The a- $\mathrm{Si}_{3} \mathrm{~N}_{4}$ films were irradiated with $120,240,360,540$ and $720 \mathrm{keV} \mathrm{C}_{60}{ }^{+, 2+}$ ions to fluences $1-$ $5 \times 10^{11}$ ions $/ \mathrm{cm}^{2}$. Neglecting the so-called cluster effect, the projected ranges of the $\mathrm{C}_{60}{ }^{+}$ ions in a- $\mathrm{Si}_{3} \mathrm{~N}_{4}$ were estimated to be 5.3, 9.4, 13.6, 19.8 and $26 \mathrm{~nm}$ at 120, 240, 360, 540 and $720 \mathrm{keV}$, respectively, using the SRIM code [21]. For comparison, some of the samples 
were irradiated with $200 \mathrm{MeV} \mathrm{Au}{ }^{14+}$ ions to fluences $5-10 \times 10^{10} \mathrm{ions} / \mathrm{cm}^{2}$.

After the ion irradiation, TEM and HAADF-STEM observations were performed using a JEOL JEM-2200FS equipped with a field emission gun operating at $200 \mathrm{kV}$. The samples were held at the specimen tilting holder with the tilt angle from -30 to 30 degrees. The images were taken by GATAN Ultrascan 1000 CCD camera with a $2 \mathrm{k} \times 2 \mathrm{k}$ pixel. In HAADF-STEM mode, a narrow electron beam converged to $0.5 \mathrm{~nm}$ diameter and an annular dark detector covering over $120 \mathrm{mrad}$ were used. The surfaces of the samples were also observed by means of atomic force microscopy (AFM, Nanoscope III) before and after ion irradiation. The AFM was operated in air under a tapping mode.

\section{Results and Discussion}

Figures 1(a) shows an example of the observed plan-view TEM images of the a- $\mathrm{Si}_{3} \mathrm{~N}_{4}$ film irradiated with $720 \mathrm{keV} \mathrm{C}_{60}{ }^{2+}$ ions. There are circular structures of almost uniform diameter of $\sim 4 \mathrm{~nm}$. Each structure has a bright core which is surrounded by a dark shell. The number of these structures agrees with the fluence of the $\mathrm{C}_{60}{ }^{2+}$ ions, indicating that single $\mathrm{C}_{60}{ }^{2+}$ impacts create individual circular structures. Similar structures were also observed for a-Si $\mathrm{N}_{3} \mathrm{~N}_{4}$ irradiated with $\mathrm{C}_{60}$ ions at different energies. Figure 1(b) - (e) show the TEM images of a- $\mathrm{Si}_{3} \mathrm{~N}_{4}$ films irradiated with $\mathrm{C}_{60}$ ions of other energies. All images show similar circular structures and the radius of the structure is almost independent of the impact energy.

It is known that impact of energetic cluster ions may create crater-like structures on the surface, which might be seen as core-shell structures in the plan-view TEM images. In order to see if the observed structures are attributed to such surface structures or not, the sample was tilted and observed by TEM. Figure 2(a) shows an example of the TEM image of the a- $\mathrm{Si}_{3} \mathrm{~N}_{4}$ film observed at a tilt angle of $25^{\circ}$, which was irradiated with $720 \mathrm{keV} \mathrm{C}{ }_{60}^{2+}$. The observed structures are elongated along the tilt direction. The observed length $(\sim 9 \mathrm{~nm})$ of the elongated structures agrees with the projected length of the ion tracks penetrating through the film, confirming that the observed structures are not surface craters. The tilted TEM images of a- $\mathrm{Si}_{3} \mathrm{~N}_{4}$ films irradiated with $240 \mathrm{keV} \mathrm{C}_{60}{ }^{+}$also show elongated structures but 
the length is shorter (Fig. 2(b)), indicating that the ion tracks do not penetrate through the film at $240 \mathrm{keV}$. This is consistent with the estimated range of $240 \mathrm{keV} \mathrm{C}_{60}{ }^{+}$ions $(9.4 \mathrm{~nm})$, which is about a half of the film thickness. This also supports the above conclusion that the observed structures are ion tracks.

The surfaces were observed using atomic force microscope (AFM). There is no signature of crater formation in the observed AFM images. The root-mean-square (RMS) roughness of the surface is about $0.3 \mathrm{~nm}$ for both before and after irradiation of $\mathrm{C}_{60}$ ions. This does not, however, exclude formation of shallow craters which may not be detected in our AFM observation. The sputtering yield for the impact of $12 \mathrm{keV} \mathrm{C}$ ion on $\mathrm{Si}_{3} \mathrm{~N}_{4}$ is estimated to be 1.1 by SRIM simulation. Taking account of the possible cluster effect, the sputtering yield might be enhanced by a factor of six [22]. Thus the sputtering yield of 720 keV $\mathrm{C}_{60}{ }^{2+}$ impact on $\mathrm{Si}_{3} \mathrm{~N}_{4}$, is estimated to be $400(=1.1 \times 60 \times 6.6)$, which corresponds to $4 \mathrm{~nm}^{3}$. If a crater of $2 \mathrm{~nm}$ radius is produced by the sputtering, the expected average depth is $\sim 0.3 \mathrm{~nm}$. Although this is a very crude estimate but this indicates that shallow craters, which cannot be observed by the present AFM observation, may be produced. The observed TEM images of the ion tracks could be affected by such shallow craters. However, the tilted TEM observation presented here indicates that such effects should be small because the observed ion tracks penetrate through the film and the ion tracks are almost uniform along the ion path when the range of the incident $\mathrm{C}_{60}$ ion is larger than the film thickness.

Figure 3 shows the energy dependence of the electronic stopping power of $\mathrm{C}_{60}{ }^{+}$ calculated using SRIM code. In this calculation, the stopping power of the mono atomic carbon ion of the same velocity was calculated and the result was simply multiplied by 60 . The electronic stopping power changes from $3.9 \mathrm{keV} / \mathrm{nm}$ to $9.7 \mathrm{keV} / \mathrm{nm}$ when the energy changes from $120 \mathrm{keV}$ to $720 \mathrm{keV}$ while the radius of the ion track is almost the same. This is somewhat strange because the radius of the ion track is known to depend strongly on the electronic stopping power. The similar tendency (no dependence of the track radius on the electronic stopping) is also seen in the tilted image for $720 \mathrm{keV}$ impact (see Fig. 2(a)). The observed radius of the ion track is almost constant along the ion path although the electronic stopping power decreases rapidly when the ion traverses the film. We will discuss this issue 
later in this paper.

The observed TEM image of the ion track has a bright core and a surrounding dark shell. This suggests that the ion track consists of a low density core and a surrounding high density shell in agreement with the SAXS observation of the ion tracks in a-SiO $2[15,16]$. The TEM contrast, however, strongly depends on focusing conditions. Figure 4 shows TEM images of the same sample observed at various focusing conditions. The observed image drastically changes when focusing conditions are changed. The contrast is even reversed in overfocused conditions, indicating that quantitative analysis is rather difficult in TEM observation as well known. In order to deduce quantitative information without suffering from the focusing problem, the same samples were observed in HAADF-STEM mode with a probe size of $0.5 \mathrm{~nm}$.

Figure 5 shows an example of the observed HAADF-STEM image for a-Si $\mathrm{N}_{4}$ irradiated with $720 \mathrm{keV} \mathrm{C}_{60}{ }^{2+}$ ions. Similarly to the TEM image, the core-shell structures are clearly seen with the reverse contrast. Because the intensity of HAADF-STEM image is proportional to the integrated density along the electron beam, the present result clearly indicates that the ion tracks consist of a low density core and a surrounding high density shell.

The radial density profiles of the ion tracks were derived from the HAADF-STEM images. Figure 6 shows the obtained profiles for $360 \mathrm{keV}, 540 \mathrm{keV}$ and $720 \mathrm{keV} \mathrm{C}_{60}{ }^{2+}$ impacts. The density is about $80 \%$ of the bulk density at the track center and increases with increasing distance $r$ from the center. The low density core is surrounded by a high density shell of which the density is $1-2 \%$ larger than the bulk density. Because the observed density enhancement is rather small, we estimated the uncertainty of the observed density enhancement. The profiles shown here were obtained by averaging about 100 measured profiles. The density in the shell region ( $r=3.2 \mathrm{~nm}$ to $4.2 \mathrm{~nm})$ normalized to the density of the background region $(r=5.3 \mathrm{~nm}$ to $6.3 \mathrm{~nm}$ ) was calculated for these 100 profiles. From these normalized densities, the average density and the standard error were estimated to be $101.2+-0.2 \%$ for $720 \mathrm{keV} \mathrm{C}_{60}{ }^{2+}$ impacts. It should be, however, noted that the observed high density shell might be explained by craters if the height of the outer rim of the crater is $0.26 \mathrm{~nm}$. 
For comparison, radial density profiles of ion tracks in $\mathrm{a}-\mathrm{SiO}_{2}$ calculated by $\mathrm{MD}$ simulation at various electronic stopping powers [16] are also shown by short dashed lines. Although the material is different, the characteristic features (low density core and surrounding high density shell) are similar to the present observation. The stopping power dependence, however, is very different between the present observation and the simulation. The observed profile changes only slightly when $S_{\mathrm{e}}$, changes from 6.8 to $9.6 \mathrm{keV} / \mathrm{nm}$ while the simulated profile changes significantly when $S_{\mathrm{e}}$ changes from 7.2 to $10.8 \mathrm{keV} / \mathrm{nm}$.

There have been indirect measurements of the ion tracks in a-Si $\mathrm{N}_{4}$ irradiated with swift heavy ions using the etching technique and FTIR [13]. The ion tracks formed in a- $\mathrm{Si}_{3} \mathrm{~N}_{4}$ are discontinuous even at $S_{\mathrm{e}} \sim 20 \mathrm{keV} / \mathrm{nm}$. In the present observation, continuous tracks of $2 \mathrm{~nm}$ radius are formed even if $S_{\mathrm{e}}$ is much smaller than $20 \mathrm{keV} / \mathrm{nm}$. Recalling that the nuclear stopping power is comparable to $S_{\mathrm{e}}$ in the present experimental conditions (see Fig. 3 ), this fact together with the above mentioned $S_{\mathrm{e}}$-dependence of the track radius can be regarded as strong indication for the effect of the nuclear stopping power on the track formation.

In order to confirm the role of the nuclear stopping power in the track formation, a film of a-Si ${ }_{3} \mathrm{~N}_{4}$ was irradiated with $200 \mathrm{MeV} \mathrm{Au}^{14+}$ ions at the tandem accelerator facility of Japan Atomic Energy Agency (JAEA). The electronic stopping power for the $200 \mathrm{MeV}$ $\mathrm{Au}^{14+}$ ions in a-Si $\mathrm{N}_{4}$ was calculated to be $14 \mathrm{keV} / \mathrm{nm}$ using CASP program [23]. This is 1.5 - 3.5 times larger than the electronic stopping powers of $120-720 \mathrm{keV} \mathrm{C}_{60}$ ions. Moreover, the charge state rapidly increases toward the equilibrium one along the trajectory. The characteristic length for achieving charge equilibrium is $2.5 \mu \mathrm{g} / \mathrm{cm}^{2}$ for $200 \mathrm{MeV} \mathrm{Au}$ ions in carbon foil [24]. This characteristic length corresponds to $8 \mathrm{~nm}$ for $\mathrm{Si}_{3} \mathrm{~N}_{4}$, indicating that the equilibrium charge state is almost achieved in the present foil. Thus, the effective $S_{\mathrm{e}}$ is even larger than $14 \mathrm{keV} / \mathrm{nm}$. Figure 7 shows examples of plan-view and tilted TEM images of the a- $\mathrm{Si}_{3} \mathrm{~N}_{4}$ film irradiated with $200 \mathrm{MeV} \mathrm{Au}^{14+}$ ions. Although ion tracks are clearly seen, the radius of the observed tracks is much smaller than that for the $\mathrm{C}_{60}$ ion impact. Moreover, the image of the tilted sample shows that the tracks are discontinuous. These results indicate that the nuclear stopping power plays an important role in the track formation. 
It was suggested the nuclear stopping power plays a certain role in the formation of ion-induced hillock structures at mica surfaces by analyzing experimental results for various ions in the wide energy range of $0.025-35 \mathrm{MeV} / \mathrm{u}$ [25]. Very recently, Toulemonde et al clearly demonstrated that the nuclear stopping power plays an important role in the track formation in the case of $0.3-15 \mathrm{MeV} \mathrm{Au}$ impacts on $\mathrm{a}-\mathrm{SiO}_{2}$ using infrared spectroscopy [24]. The present direct observations by TEM and HAADF-STEM confirm their result.

As was mentioned above, we cannot exclude the surface effects on the observed ion tracks. It should be, however, noted that the present result demonstrates that the density change of several $\%$ in amorphous materials can be easily observed by TEM and HAADF-STEM. Since MD simulations predicted much larger density change in the ion tracks produced in amorphous $\mathrm{SiO}_{2}$, the present result indicates that TEM and HAADF-STEM have potential to shed light on the mechanism of the ion track formation in bulk amorphous materials.

\section{Conclusion}

Ion tracks produced by $120-720 \mathrm{keV} \mathrm{C}_{60}{ }^{+, 2+}$ impacts on amorphous $\mathrm{Si}_{3} \mathrm{~N}_{4}$ thin films were directly observed using TEM and HAADF-STEM. The observed ion tracks are continuous and the density is reduced by $20 \%$ at the track center. The low density region extends up to $\sim 2.5 \mathrm{~nm}$ from the center. This low density core is surrounded by a slightly high density shell. The density of the shell is $1-2 \%$ higher than the bulk density and the width of the shell is $\sim 2.5 \mathrm{~nm}$. Although we cannot exclude possible surface effects on the observed ion tracks, especially on the high density shell, the observed track structure is very similar to the ion tracks in a-SiO 2 irradiated with high energy heavy ions observed by SAXS. Differently from a-SiO $2, a-\mathrm{Si}_{3} \mathrm{~N}_{4}$ does not have density anomaly. This suggests that the density anomaly does not play an important role in the formation of the core-shell structure.

The ion tracks are also observed in $\mathrm{a}-\mathrm{Si}_{3} \mathrm{~N}_{4}$ films irradiated with $200 \mathrm{MeV} \mathrm{Au}{ }^{14+}$ ions. The radius of the track, however, is much smaller than that for $120-720 \mathrm{keV} \mathrm{C}_{60}$ ions and the track is discontinuous although the effective electronic stopping power for $200 \mathrm{MeV} \mathrm{Au}^{14+}$ ion is comparable to those for $120-720 \mathrm{keV} \mathrm{C}_{60}$ ions. This indicates that the nuclear stopping 
power is also responsible for the track formation and is even more efficient than the electronic stopping power.

Acknowledgement

The authors are grateful to the crew of the $400-\mathrm{kV}$ ion implanter at JAEA/Takasaki, which was used for the irradiation of $\mathrm{C}_{60}{ }^{+}$. This work was supported by Grant-in-Aid for Exploratory Research from JSPS (Grant Number 24651114).

\section{References}

[1] E.C.H. Silk and R.S. Barnes, Philos. Mag. 4 (1959) 970.

[2] A. Meftah, F. Brisard, J.M. Costantini, E. Dooryhee, M. Hage-Ali, M. Hervieu, J.P. Stoquert, F. Studer, M. Toulemonde, Phys. Rev. B 49 (1994) 12457.

[3] M. Toulemonde et al., Nucl. Instrum. Methods Phys. Res., Sect. B 39 (1989) 1.

[4] M. Levalois, P. Bogdanski, and M. Toulemonde, Nucl. Instrum. Methods Phys. Res., Sect. B 63 (1992) 14.

[5] W. Wesch, A. Kamarou, and E. Wendler, Nucl. Instrum. Methods Phys. Res., Sect. B 225 (2004) 111.

[6] A. Barbu, A. Dunlop, D. Lesueur, R.S. Averbsck, Europhys. Lett. 15 (1991) 37.

[7] C. Dufour, A. Audouard, F. Beuneu, J. Dural, J. P. Girard, A. Hairie, M. Levalois, E. Paumier and M. Toulemonde, J. Phys. Condens. Matter 5 (1993) 4573.

[8] A. Dunlop and D. Lesueur, Radiat. Eff. Defects Solids 126 (1993) 123.

[9] A. Meftah, J.M. Costantini, N. Khalfaoui, S. Boudjadar, J.P. Stoquert, F. Studer, M. Toulemonde, Nucl. Instrum. Methods Phys. Res., Sect. B 237 (2005) 563.

[10] Klaumünzer, Mat. Fys. Med. 52 (2006) 293.

[11] N. Itoh, D. M. Duffy, S. Khakshouri and A.M. Stoneham, J. Phys. Condens. Matter 21 (2009) 474205 .

[12] M.C. Busch, A. Slaoui, P. Siffert, E. Dooryhee, M. Toulemonde, J. Appl. Phys. 71 (1992) 2596. 
[13] B. Canut, A. Ayari, K. Kaja, A.-L. Deman, M. Lemiti, A. Fave, A. Souifi, S. Ramos, Nucl. Instrum. Methods Phys. Res., Sect. B 266 (2008) 2819.

[14] C. Milanez Silva, P. Varisco, A. Moehlecke, P.P. Fichtner, R.M. Papaleo, J. Eriksson, Nucl. Instrum. Methods Phys. Res., Sect. B 206 (2003) 486.

[15] P. Kluth, C.S. Schnohr, D.J. Sprouster, A.P. Byrne, D.J. Cookson, M.C. Ridgway, Nucl. Instrum. Methods Phys. Res., Sect. B 266 (2008) 2994.

[16] P. Kluth, C.S. Schnohr, O.H. Pakarinen, F. Djurabekova, D.J. Sprouster, R. Giulian, M.C. Ridgway, A.P. Byrne, C. Trautmann, D.J. Cookson, K. Nordlund, M. Toulemonde, Phys. Rev. Lett. 101 (2008) 175503.

[17] O.H. Pakarinen, F. Djurabekova, K. Nordlund, P. Kluth and M.C. Ridgway, Nucl. Instrum. Methods Phys. Res., Sect. B 267 (2009) 1456.

[18] O.H. Pakarinen, F. Djurabekova and K. Nordlund, Nucl. Instrum. Methods Phys. Res., Sect. B 268 (2010) 3163.

[19] A. Dunlop, J. Henry and G. Jaskierowicz, Nucl. Instrum. Methods Phys. Res., Sect. B 146 (1998) 222.

[20] G. Rizza, A. Dunlop, G. Jaskierowicz and M. Kopcewicz, Nucl. Instrum. Methods Phys. Res., Sect. B 226 (2004) 609.

[21] J.F. Ziegler, J.P. Biersack, U.L. Littmark, The Stopping and Range of Ions in Solids, Pergamon Press, New York, 1985.

[22] The sputtering yield for impact of $540 \mathrm{keV} \mathrm{C}_{60}{ }^{2+}$ on Si was measured to be $\sim 250$ while sputtering yield for $9 \mathrm{keV} \mathrm{C}^{+}$is estimated to be 0.7 by SRIM. The enhancement factor due to the cluster effect is about $\operatorname{six}(=250 /(60 \times 0.7))$.

[23] P.L. Grande and G. Schiwietz, Nucl. Instrum. Methods Phys. Res., Sect. B 267 (2009) 859.

[24] M. Toulemonde, Nucl. Instrum. Methods Phys. Res., Sect. B 250 (2006) 263.

[25] G. Szenes, Nucl. Instrum. Methods Phys. Res., Sect. B 191 (2002) 27.

[26] M. Toulemonde, W.J. Weber, G. Li, V. Shutthanandan, P. Kluth, T. Yang, Y. Wang and Y. Zhang, Phys. Rev. B 83 (2011) 054106. 
Figure captions

Fig. 1 TEM bright field images of a-Si ${ }_{3} \mathrm{~N}_{4}$ film (20 nm) irradiated with (a) $720 \mathrm{keV}$, (b) 540 $\mathrm{keV}$, (c) $360 \mathrm{keV}$, (d) $240 \mathrm{keV}$ and (e) $120 \mathrm{keV} \mathrm{C}_{60}{ }^{+}$ions to a fluence of $\sim 2 \times 10^{11} \mathrm{ions} / \mathrm{cm}^{2}$.

Fig. 2 TEM bright field images of a-Si ${ }_{3} \mathrm{~N}_{4}$ film $(20 \mathrm{~nm})$ irradiated with (a) $720 \mathrm{keV} \mathrm{C}_{60}{ }^{+}$ ions and (b) $240 \mathrm{keV} \mathrm{C} 60{ }^{2+}$ ions to a fluence of $\sim 2 \times 10^{11}$ ions $/ \mathrm{cm}^{2}$. The images observed with the film tilted by $25^{\circ}$ with respect to the electron beam. The projectile propagation direction is indicated by the arrow.

Fig. 3 Electronic and nuclear stopping powers of $\mathrm{C}_{60}$ ions in a-Si $\mathrm{N}_{3}$ film calculated using SRIM code. The cluster effect was neglected (see text).

Fig. 4 TEM images of a-Si $\mathrm{N}_{4}$ film $(20 \mathrm{~nm})$ irradiated with $540 \mathrm{keV} \mathrm{C}_{60}{ }^{+}$ions. Bright field images observed in (a) underfocused, (b) focused and (c) overfocused conditions.

Fig. 5 HAADF-STEM image of a-Si $\mathrm{N}_{4}$ film irradiated with $720 \mathrm{keV} \mathrm{C}_{60}{ }^{2+}$ ions to a fluence of $\sim 2 \times 10^{11}$ ions $/ \mathrm{cm}^{2}$.

Fig. 6 Radial density profiles of the ion track obtained from the observed HAADF-STEM images of a-Si $\mathrm{N}_{4}$ films irradiated with $360 \mathrm{keV}$ (dot-dashed line), $540 \mathrm{keV}$ (dashed line) and $720 \mathrm{keV} \mathrm{C}_{60}{ }^{2+}$ ions (solid line). The results of $\mathrm{MD}$ simulation [16] for $\mathrm{a}-\mathrm{SiO}_{2}$ at various stopping powers are also shown by short dashed lines.

Fig. 7 TEM bright field images of a-Si ${ }_{3} \mathrm{~N}_{4}$ film $(20 \mathrm{~nm})$ irradiated with $200 \mathrm{MeV} \mathrm{Au}$ ions to a fluence of $\sim 1 \times 10^{11}$ ions $/ \mathrm{cm}^{2}$. The images observed with the film normal (a) and tilted by $25^{\circ}$ (b) with respect to the electron beam are shown. The tracks are inhomogeneous. The projectile propagation direction is indicated by the arrow. 


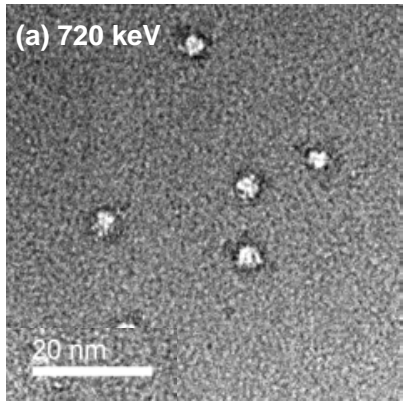

Fig. 1(a)

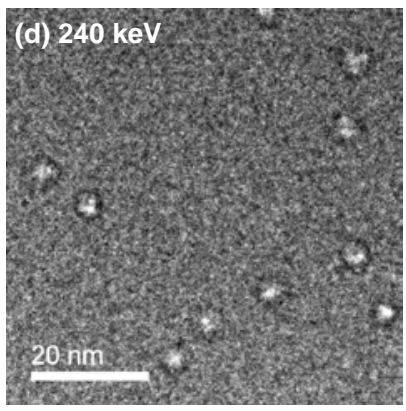

Fig. 1 (d)

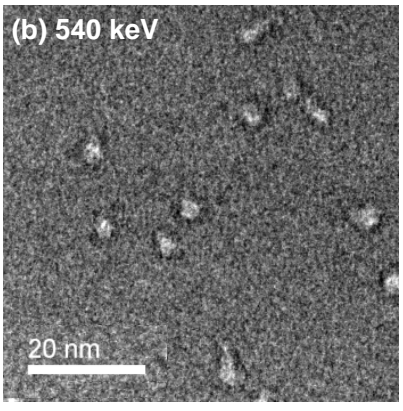

Fig. 1(b)

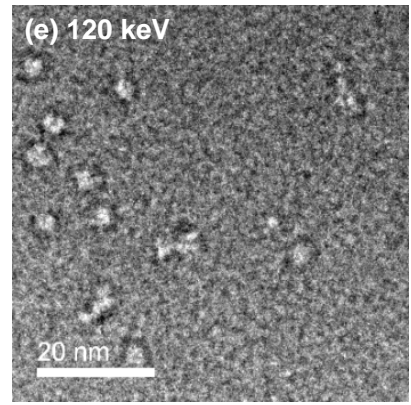

Fig. 1(e)

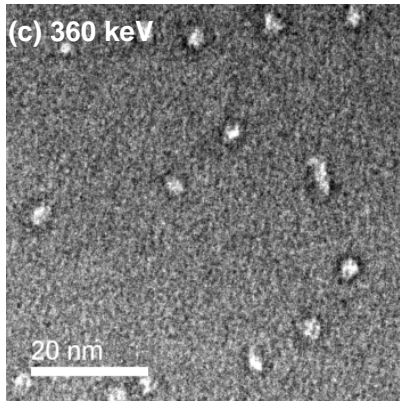

Fig. 1(c)

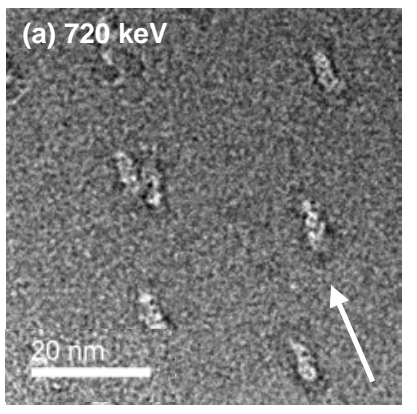

Fig. 2(a)

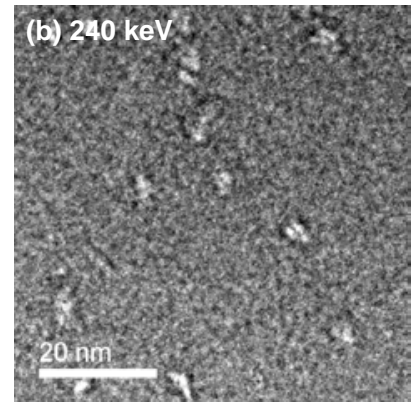

Fig. 2(b) 


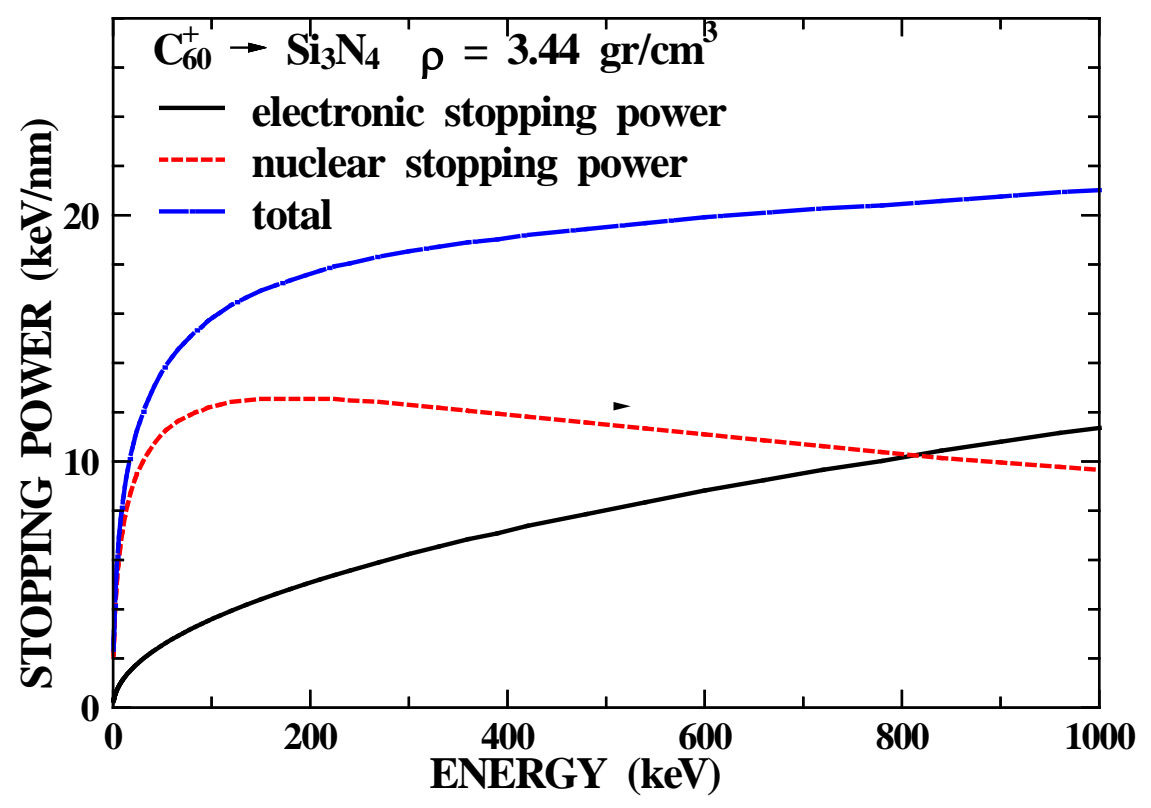

Fig. 3

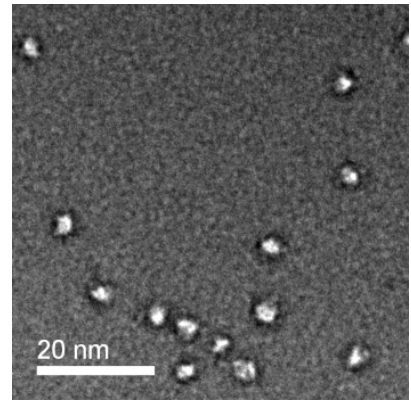

Fig. 4 (a)

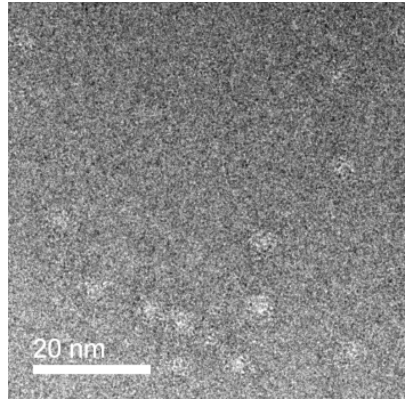

Fig. 4 (b)

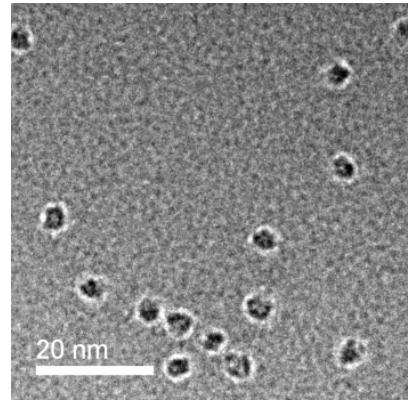

Fig. 4 (c)

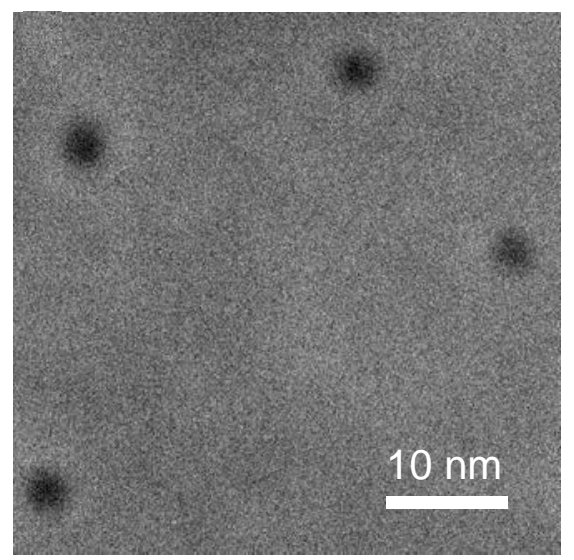

Fig. 5 


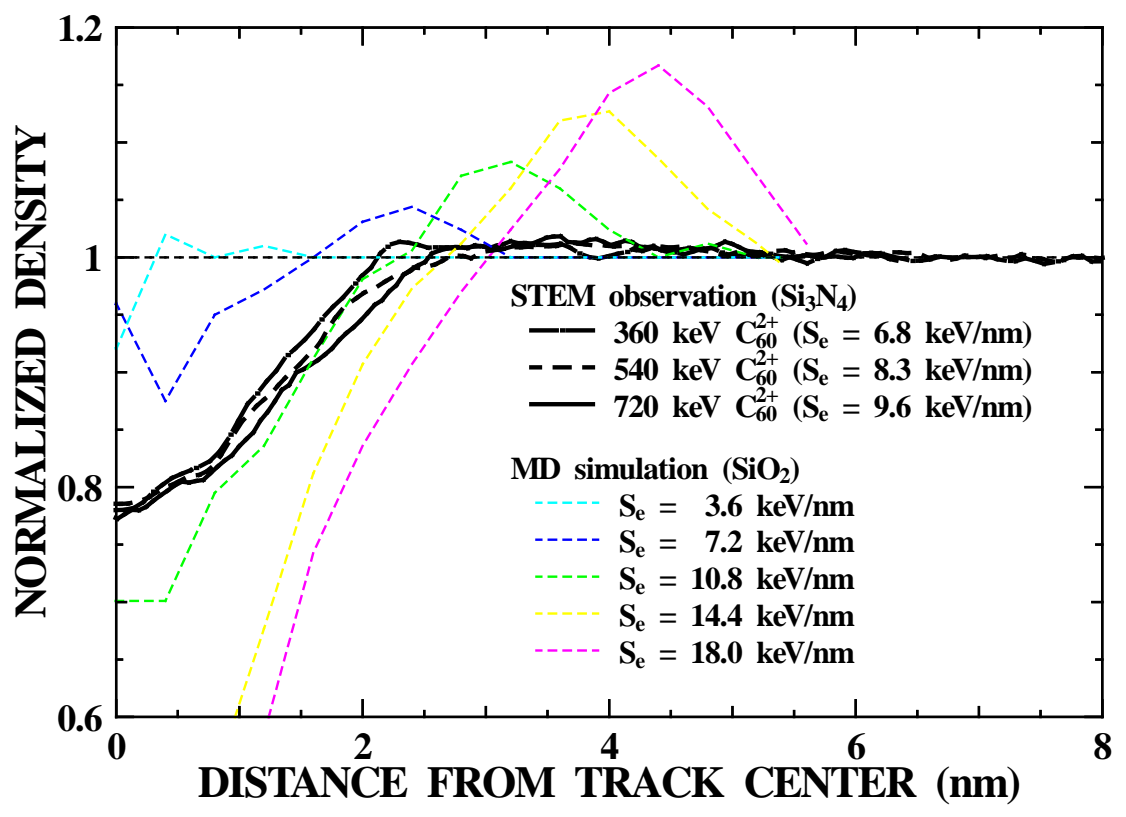

Fig. 6

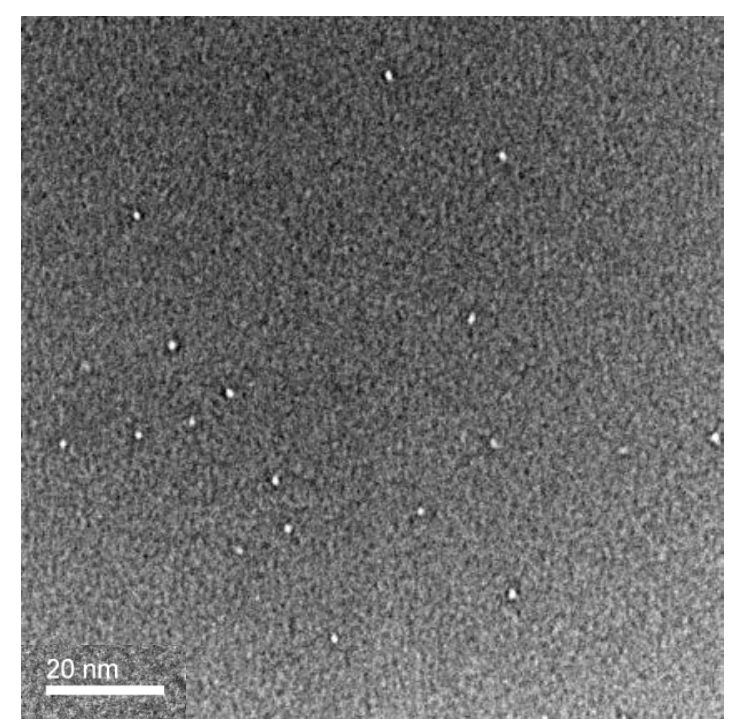

Fig. 7 (a)

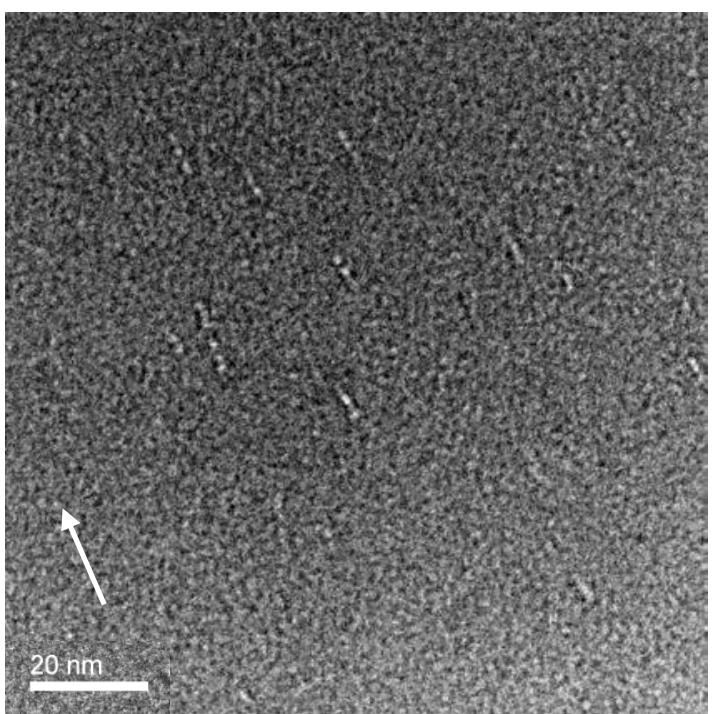

Fig. 7 (b) 